\title{
Expression profiles of immune mediators in feline Coronavirus-infected cells and clinical samples of feline Coronavirus-positive cats
}

\author{
Nikoo Safi ${ }^{1,3}$, Amin Haghani ${ }^{1,3}$, Shing Wei $\mathrm{Ng}^{1}$, Gayathri Thevi Selvarajah ${ }^{2}$, Farina Mustaffa-Kamal ${ }^{2 *}$ \\ and Abdul Rahman Omar ${ }^{1,2}$
}

\begin{abstract}
Background: There are two biotypes of feline coronavirus (FCoV): the self-limiting feline enteric coronavirus (FECV) and the feline infectious peritonitis virus (FIPV), which causes feline infectious peritonitis (FIP), a fatal disease associated with cats living in multi-cat environments. This study provides an insight on the various immune mediators detected in FCoV-positive cats which may be responsible for the development of FIP.

Results: In this study, using real-time PCR and multiplex bead-based immunoassay, the expression profiles of several immune mediators were examined in Crandell-Reese feline kidney (CRFK) cells infected with the feline coronavirus (FCoV) strain FIPV 79-1146 and in samples obtained from FCoV-positive cats. CRFK cells infected with FIPV 79-1146 showed an increase in the expression of interferon-related genes and pro-inflammatory cytokines such as MX1, viperin, CXCL10, CCL8, RANTES, KC, MCP1, and IL8. In addition, an increase in the expression of the above cytokines as well as GM-CSF and IFNy was also detected in the PBMC, serum, and peritoneal effusions of FCoV-positive cats. Although the expression of MX1 and viperin genes was variable between cats, the expression of these two genes was relatively higher in cats having peritoneal effusion compared to cats without clinically obvious effusion. Higher viral load was also detected in the supernatant of peritoneal effusions compared to in the plasma of FCoV-positive cats. As expected, the secretion of IL1 $\beta$, IL6 and TNFa was readily detected in the supernatant of peritoneal effusions of the FCoV-positive cats.

Conclusions: This study has identified various pro-inflammatory cytokines and interferon-related genes such as MX1, viperin, CXCL10, CCL8, RANTES, KC, MCP1, IL8, GM-CSF and IFNy in FCoV-positive cats. With the exception of MX1 and viperin, no distinct pattern of immune mediators was observed that distinguished between FCoV-positive cats with and without peritoneal effusion. Further studies based on definitive diagnosis of FIP need to be performed to confirm the clinical importance of this study.
\end{abstract}

Keywords: Feline Coronavirus, Cytokine, Immune-mediators

\section{Background}

Feline coronavirus (FCoV) can be divided into two biotypes: the ubiquitous feline enteric coronavirus (FECV) which often causes self-limiting diarrhea, and the feline infectious peritonitis virus (FIPV), the mutated form which causes fatal disease in cats $[1,2]$. The widely accepted 'internal mutation' theory describes that mutations in FECV give rise to FIP de novo. In addition, it

\footnotetext{
* Correspondence: farina@upm.edu.my

${ }^{2}$ Faculty of Veterinary Medicine, Universiti Putra Malaysia, Serdang, Selangor, Malaysia

Full list of author information is available at the end of the article
}

was suggested that these mutations occur in the monocytes, rather than the intestinal epithelial cells where the FECV first enters the host $[3,4]$. FCoV travels to organs and tissues through monocyte-associated viremia where it is later disseminated in the endothelial venules of the serosa, omentum, pleura, meninges and uveal tract (reviewed in $[1,2])$.

Currently, there are no specific markers to distinguish the two biotypes, thus making the diagnosis of feline infectious peritonitis (FIP) difficult. Although several studies have reported several point mutations in the $\mathrm{S}$ gene that are associated with occurrence of FIPV, it 
remains unclear whether the mutations contributed solely to the development of FIP [5-7]. Therefore, antemortem confirmation of FIP remains a challenging task in clinical research of FIP.

Information on the immunopathogenesis and the role of cytokines, and immune mediators in FCoV infection are relatively sparse. Although it is generally known that FECV causes self-limiting disease, cats can become persistent shedders contributing to the transmission of the disease (reviewed in $[1,2]$ ). However, only approximately $5 \%$ of cats harboring FECV actually develop FIP $[1,8]$. The exact nature of this immunity is still unknown although the development of FIP has been postulated to correlate with the magnitude of immune responses, as cats with robust cell-mediated immune (CMI) response have been found to resist the disease [9]. In contrast, humoral response does not seem to be beneficial and could lead to the dissemination of the virus through complement activation via formation of immune complexes and vasculitis associated with type III hypersensitivity (reviewed in [1,2]). This would then lead to effusive FIP (wet form), the most commonly reported form of FIP due to the obvious sign of peritoneal effusion. The non-effusive form of FIP is associated with partial CMI response in the individual cat to contain the virus leading to the formation of granulomas containing macrophages, which could then be replaced by $B$ cells and plasma cells $[10,11]$.

To date, there are no specific immune markers that could distinguish FECV from FIPV infections. However, the observed cytokine patterns are different between asymptomatic FCoV-infected cats and those with clinical signs of FIP [12]. Asymptomatic FCoV-infected cats generally show higher IL10 in the spleen, suggesting the ability to control excessive inflammation triggered by macrophages. Furthermore, lymphocyte depletion has been indicated as one of the hallmarks of FIP and postulated to be induced by excessive production of TNF $\alpha$ [13-15]. In contrast, high IFN $\gamma$ and IL $1 \beta$ production has been associated with protection against FIP [16]. Increase in Th1-like cytokines such as IL12/p40 and IFN $\gamma$, which were associated with the decrease of IL4 in the lymphoid tissue, has been observed in cats experimentally infected with FIPV [13]. Furthermore, previous studies showed deregulation of different mediators, illustrated by the upregulation of pro-inflammatory cytokines such as IL1ß, IL6, TNF $\alpha$, MIP1 $\alpha$, RANTES, and IFN $\gamma$ in peritoneal effusions and serum samples of FIP clinical cases [17-19].

Recently, we used a transcriptomic approach by nextgeneration sequencing of RNA from Crandell-Reese feline kidney (CRFK) cells infected with the FCoV strain FIPV 79-1146 to elucidate the complex interaction between the virus and host cells in vitro [20,21]. Results revealed that, during the first $3 \mathrm{~h}$ of infection, at least 96 transcripts associated with immune responses (e.g. ISGs, MX1, RSAD2, A3C, ID1, CRIP1, TRIM25 and MDA5), apoptosis (ID1, ATF3, TNFa, and RNF7), and proinflammatory responses (e.g. PD-L1, CCL8, CXCL10 and CCL17) were downregulated. Only a few genes, namely PD-1, PD-L1 and A3H, has been previously characterized in a study on FCoV-infected CRFK cells and expression profiles in peripheral blood mononuclear cells (PBMC) of cats diagnosed with FIP [20]. Characterization of additional immune mediators that modulate innate and acquired immune responses will increase our understanding of their involvement during FIPV infection. The objective of this study was to investigate the immune mediator profiles in CRFK-infected cells and FCoV-positive cats. Both gene and protein expression profiles were determined by quantitative real-time PCR (qPCR) and multiplex bead-based assays.

\section{Methods}

In vitro analysis of FCoV-infected cells

TCID50 of the FCoV strain FIPV 79-1146 (ATCC VR2202) [22] was determined using endpoint dilution assay. Virus infectivity was confirmed by RT-PCR (Bioline, UK) detecting the FCoV conserved 3' untranslated region (3'-UTR) [23]. To prepare a sufficient amount of infected cells at different time points, two confluent $75 \mathrm{~cm}^{2}$ flasks of CRFK cells (ATCC ${ }^{\circ}$ CCL-94 $4^{\text {ma }}$ ) were inoculated at each time point with $3 \mathrm{ml} \mathrm{TCID}{ }_{50} / \mathrm{ml}(\mathrm{MOI}=0.1)$ of FIPV 791146 and the virus inoculum was left in the culture. At 3 , 12, 24, 48 and $72 \mathrm{~h}$ post-inoculation (hpi), the cells were trypsinized and cell pellets were collected upon centrifugation. The uninfected flask was designated as 0 hpi. The cell pellets were stored at $-80{ }^{\circ} \mathrm{C}$ until further use for virus and immune mediator detection by real-time PCR and multiplex bead-based immunoassay.

\section{Selection criteria for FCoV-positive cats}

Before performing the in vivo phase of the study, approval for handling and sampling cats was obtained from the Institutional Animal Care and Use Committee (IACUC), Faculty of Veterinary Medicine, Universiti Putra Malaysia (UPM) with the reference number UPM/ IACUC/AUP-R040/2014. The status of FCoV infection was evaluated in cats that were presented to the University Veterinary Hospital (UVH), UPM, using Biogal's Immunocomb Antibody Test Kit (Biogal-Galed Laboratories, Israel) to determine the antibody titer, followed by reverse transcriptase quantitative PCR (RT-qPCR) to detect the presence of FCoV in the serum [23]. Combscale $S$ value was used as a colorimetric indicator for the determination of anti-FCoV antibody titer, where cats with antibody titers $\geq \mathrm{S} 2+$ were chosen for further analysis [24]. In addition, cats were also screened serologically for Feline Immunodeficiency Virus (FIV) and Feline Leukemia Virus 
(FELV) using the SNAP FIV/FELV Combo test (IDEXX Laboratories, USA) according to the manufacturer's protocol. Cats with high antibody levels against FCoV (titer $\geq \mathrm{S} 2+$ ) and that are seronegative for FIV and FELV were selected and further underwent hematology evaluation. In addition to that, the presence or absence of peritoneal effusion was also evaluated in these selected cats. Post-mortem examination and follow-up analysis were not carried out to arrive at definitive diagnosis of FIP. Healthy seronegative FIV/FELV cats with absence of antibody titer against FCoV were considered as negative control cats.

\section{Blood collection for preparation of PBMC and plasma} A total of $2.5 \mathrm{ml}$ blood was collected from $\mathrm{FCoV}$ antibody titer $\geq$ S2+, FIV- and FELV- cats. The collected blood samples were immediately divided into two tubes for different purposes. First, $0.5 \mathrm{ml}$ of blood was stored in clot activator tubes (BD Vacutainer ${ }^{\circ}$ Tubes with BD hemoguard closure, USA) on ice and kept at $4{ }^{\circ} \mathrm{C}$ for serum separation. The remainder of the blood was transferred into EDTA tubes (BD Vacutainer ${ }^{\circ}$ Tubes with BD hemoguard closure, USA) for PBMC isolation and plasma collection. The collected serum was stored at $-80{ }^{\circ} \mathrm{C}$ for multiplex bead-based immunoassay. Isolation of PBMC was performed using Ficoll-Paque PLUS (GE Healthcare Life Science, USA) following the steps provided by the manufacturer. Plasma and PBMC were collected separately and stored at $-80{ }^{\circ} \mathrm{C}$ until further use in real-time PCR for measuring viral load and mRNA expression of immune-related genes.

\section{Peritoneal effusion}

Peritoneal effusion (PE) samples were collected from FCoV-positive cats and centrifuged at $400 \times g$ for $10 \mathrm{~min}$ at $4{ }^{\circ} \mathrm{C}$. The obtained cell pellets were used for detecting expression of immune-related genes using real-time PCR, whereas the supernatants were used for virus detection using RT-qPCR and for measuring cytokine and chemokine levels using multiplex bead-based immunoassay.

\section{RNA extraction}

Cellular RNA was extracted from the CRFK, PBMC and PE cells using the RNeasy Mini Kit, which includes DNase treatment (Qiagen, Germany), following the protocol supplied by the manufacturer. Viral RNA was extracted from the cell culture pellet, plasma, and supernatant of the PE (PES) using the Viral Nucleic Acid Extraction Kit 2 (Geneaid, Taiwan) according to the manufacturer's instructions. The concentration and quality of the extracted RNA were analyzed using a BioSpectrometer (Eppendorf, Germany). The extracted
RNA samples (100 ng/ $\mu \mathrm{l})$ were used immediately to synthesize cDNA or kept at $-80{ }^{\circ} \mathrm{C}$ for future usage.

\section{Detection of viral load by SYBR green-based real-time PCR} cDNA was synthesized using the SensiFAST ${ }^{\mathrm{Tw}}$ cDNA Kit (Bioline, UK), as instructed by the manufacturer. Virus quantification was performed using SYBR Green-based real-time PCR as described previously with a slight modification [25]. Briefly, quantitative real-time PCR (qPCR) was performed in a $20 \mu \mathrm{l}$ reaction consisting of $1 \mu \mathrm{l} \mathrm{cDNA}, 1 \mu \mathrm{l}$ forward primer $(1 \mu \mathrm{mol}), 1 \mu \mathrm{l}$ reverse primer $(1 \mu \mathrm{mol}), 7 \mu \mathrm{l}$ nuclease-free water and $10 \mu \mathrm{l} 2 \times$ SensiFAST SYBR $^{\circ}$ No-ROX mix (Bioline, UK). The qPCR reaction was performed using the CFX96 Touch TM Real-Time PCR Detection System (Bio-Rad, USA) with the following cycling conditions: one cycle at $95^{\circ} \mathrm{C}$ for PCR activation and 40 cycles of denaturation at $95^{\circ} \mathrm{C}$ for $5 \mathrm{~s}$, annealing at $60^{\circ} \mathrm{C}$ for $10 \mathrm{~s}$, and extension at $70{ }^{\circ} \mathrm{C}$ for $20 \mathrm{~s}$. Detection of viral load was done by absolute quantification based on a standard curve generated from the serial dilution of a cDNA template. Viral load was expressed as viral copy number following a formula described previously [26].

\section{Detection of immune-related mRNA expression by TaqMan-based real-time PCR}

The expression of five immune-related genes, namely CCL8 (MCP2), viperin (RSAD2), CXCL10, MX1, and CCL17, and one reference gene (GAPDH) was measured by TaqMan-based real-time PCR (qPCR). The forward primers, reverse primers and TaqMan MGB probes were designed based on the Felis catus genome sequence [27]. The sequences of the primers and probes were designed using the CLC genomic workbench software, while primer characteristics were analyzed using Primer3 (http:// bioinfo.ut.ee/primer3-0.4.0/) and Basic Local Alignment Search Tool (BLAST) to confirm alignment with more than $80 \%$ of the related gene in the Felis catus genome (Applied Biosystem, USA) (Table 1). cDNA was prepared using the Tetro cDNA Synthesis Kit (Bioline, UK) according to the manufacturer's protocol with a slight modification, in which specific forward and reverse primers for each gene were used instead of random hexamers. The RNA extracted from FIPV-infected CRFK cells at 48 hpi was used to optimize the real-time PCR assay before the assay was used to measure expression in the clinical samples obtained from FCoV-positive cats. Using serially diluted cDNA of each gene, the designed primer sets produced specific amplification with high PCR efficiency. Furthermore, primers for each gene were designed spanning two different exons to ensure specificity.

qPCR was performed using the TaqMan Fast Advanced Master Mix (Life Technologies ${ }^{\oplus}$ Applied Biosystems, 
Table 1 TaqMan primers, MGB probes and accession numbers of the analyzed immune-related genes

\begin{tabular}{|c|c|c|c|c|}
\hline Gene & Primers sequences & MGB Probe & Accession number & $\begin{array}{l}\text { Annealing } \\
\text { temperature }\left({ }^{\circ} \mathrm{C}\right)\end{array}$ \\
\hline CCL8 & $\begin{array}{l}\text { 117CTTGCTCAGCCAGGTTCAGTT137 } \\
\text { 183GGATCTTCCCTTGACCACACT162 }\end{array}$ & 6FAMCCATCCCAATTACCTGCTMGBNFQ & XM_003996558 & 66 \\
\hline Viperin & $\begin{array}{l}\text { 219CCCCCACCAGCGTCAAC235 } \\
\text { 281GGAAGCAGAAGCCACACTTGT261 }\end{array}$ & 6FAMACCACTTCACCCGCCAGMGBNFQ & XM_003984516 & 60 \\
\hline CXCL10 & $\begin{array}{l}\text { 332ACACAGAAGCATAATCACCGTACTG356 } \\
\text { 399GGGAAATGATGGCAGAGGTAGT378 }\end{array}$ & 6FAMCAAAGATGGACCAGAAAGMGBNFQ & XM_003985274 & 60 \\
\hline$M \times 1$ & $\begin{array}{l}\text { 469CAGGACTITGAGACGGAGATTTC491 } \\
\text { 535CATTCTGGGCTGTATTGATTGC514 }\end{array}$ & 6FAMCCCTTCGGAGGTGGAMGBNFQ & XM_006935851 & 60 \\
\hline CCL17 & $\begin{array}{l}\text { 119GGGCCATCCCTCTCAGAAG137 } \\
\text { 189CACTATGGCGTCTITGGAACACT167 }\end{array}$ & 6FAMTGACAGGGTGGTACAGGAMGBNFQ & NM_001009849 & 60 \\
\hline $\mathrm{GAPDH}^{\mathrm{a}}$ & $\begin{array}{l}\text { 71GTCCCCGAGACACGATGGT89 } \\
\text { 130CCAGGCGCCCAATACG115 }\end{array}$ & 6FAMAAGGTCGGAGTCAACGGMGBNFQ & XM_006933438 & 57 \\
\hline
\end{tabular}

Note: ${ }^{\text {Reference gene }}$

USA) according to the manufacturer's protocol. $20 \mu \mathrm{l}$ reactions were prepared as follows: $1 \mu \mathrm{l}$ cDNA template, $0.5 \mu \mathrm{l}$ forward primer $(450 \eta \mathrm{M}), 0.5 \mu \mathrm{l}$ reverse primer $(450$ $\eta \mathrm{M}), 1 \mu \mathrm{l}$ probe $(250 \eta \mathrm{M}), 7 \mu \mathrm{l}$ nuclease-free water and $10 \mu \mathrm{l}$ of Fast Advanced Master Mix. The Taqman Fast Advanced Master Mix consisted of AmpliTaq Fast DNA Polymerase, Uracil-N-glycosylase (UNG), dNTPs with dUTP, ROX dye, and optimized buffer components. RTqPCR was performed on the CFX96 Touch TM RealTime PCR Detection System (Bio-Rad, USA) with the following steps: initial UNG incubation at $50{ }^{\circ} \mathrm{C}$ for $2 \mathrm{~min}$ and PCR activation at $95^{\circ} \mathrm{C}$ for $20 \mathrm{~s}$, followed by 40 cycles of denaturation at $95{ }^{\circ} \mathrm{C}$ for $5 \mathrm{~s}$, annealing at optimized temperature for $10 \mathrm{~s}$ (Table 1), and extension at $72{ }^{\circ} \mathrm{C}$ for 20 s. The PCR efficiency of GAPDH, CXCL10, MX-1, viperin, CCL17 and CCL8 was 100, 99, 101, 102, 100 and $100 \%$, respectively. For data interpretation, relative expression analysis $(\Delta \Delta \mathrm{Cq})$ followed by analysis of variance (ANOVA) $(p<0.05)$ were carried out to determine the expression changes of target genes across different time points. Relative expression of the different immunerelated genes were normalized to GAPDH and the negative controls.

\section{Detection of immune-related protein expression by multiplex bead-based immunoassay}

Measurement of 19 different immune-related protein expression was performed using the feline cytokines/ chemokine magnetic bead-based panel immunoassay, FCYTOMAG-20 K FCYTMAG-20 K-PMX (MILLIPLEX MAP Kit, EMD Millipore Corporation, USA) following the manufacturer's instructions. The assay's principle of quantitative analysis was based on the standard provided in the kit. The standard was a mixture of all immunerelated proteins at certain concentrations prepared by dilution as described by the kit. Hence, the concentrations of immune-related proteins in the samples were measured using the standard curve generated by the standard. The prepared incubated plates (containing samples, standard and quality controls) were read on a Luminex analyzer (MAGPIX). Data obtained from the analyzer were analyzed by the MILLIPLEX analyst v5.1 software using five parameters logistic regression (EMD Millipore).

\section{Statistical analysis}

Data generated from this study were represented as means \pm standard error of the mean (SEM). Statistical package for the social sciences (SPSS) version 22 was used to perform factorial analysis of variance (ANOVA) at 0.05 levels of significance for both the in vitro and in vivo experiments. Duncan test was used for post hoc analysis between the groups.

\section{Results}

Detection of viral load

Viral load in the infected cells was detected based on the 3' UTR region of FIPV using SYBR green-based real-time PCR. An increase in viral load was detected at different time points, with the peak viral load of $10^{12.54}$ occurring at $48 \mathrm{hpi}$, while the lowest viral load was detected at $3 \mathrm{hpi}$ (Table 2). Total RNA obtained from the CRFK cells at 72 hpi was used to optimize the real-time PCR. The real-time PCR assay has a PCR efficiency of $100 \%$.

\section{Expression profiles of immune-related genes in FIPV 79-1146-infected cells}

All the analyzed immune-related genes showed significant $(p<0.05)$ changes in expression levels at different time points following infection with FCoV strain FIPV 791146. These genes were selected based on transcriptome data from our previous study on CRFK cells infected with FIPV 79-1146 [14]. In this study, we confirmed the upregulation of these genes at $3 \mathrm{hpi}$ using Taqman real-time PCR. CCL8 and MX1 showed peak expression levels at 48 hpi, while CXCL10 and viperin showed the highest 
Table 2 Intracellular FCoV load in CRFK cells at different time points post infection

\begin{tabular}{ll}
\hline Time points (hpi) & $\begin{array}{l}\text { FCoV copy number } \\
\text { [Mean } \pm \text { SEM (log10)] } \\
\end{array}$ \\
\hline $0^{\mathrm{a}}$ & Intracellular \\
$3^{\mathrm{b}}$ & - \\
$12^{\mathrm{d}}$ & $5.22 \pm 0.12$ \\
$24^{\mathrm{c}}$ & $10.28 \pm 0.06$ \\
$48^{\mathrm{f}}$ & $6.33 \pm 0.02$ \\
$72^{\mathrm{e}}$ & $12.54 \pm 0.34$ \\
\hline
\end{tabular}

Note: Different alphabets indicate significant difference $(p<0.05)$ following Duncan post hoc analysis of three replicates from three independent experiments

expression at 72 hpi (Table 3). Although the expression of viperin was upregulated at 48 and $72 \mathrm{hpi}$, its expression was downregulated at 3 and 12 hpi (Table 3 ).

\section{Detection of immune-related proteins in FIPV 79-1146-} infected CRFK cells

A total of 19 different immune-related proteins were analyzed by a bead-based multiplex immunoassay at different time points, following infection with FIPV 79-1146. The panel of proteins was chosen since it comprised of mediators with known functions in antiviral immunity, modulation of pro-inflammatory responses and regulation of viral-induced apoptosis. Out of the 19 immune-related proteins, only IL8 (CXCL8), KC (CXCL1), RANTES (CCL5) and MCP1 (CCL2) were detected in the CRFK-infected cells (Table 4). We were unable to detect the expression of other proteins, most likely due to the nonhematopoietic origin of CRFK cells whereby they did not secrete the proteins and/or the expression levels were too low beyond the detection limit of the assay.

FIPV infection of CRFK cells caused a significant modulation in the expression of the detectable cytokines, with peak expression detected at $48 \mathrm{hpi}$ (CCL2 and CCL5) or 72 hpi (CXCL1 and CXCL8). However, CXCL8 and CCL5 were downregulated at $3 \mathrm{hpi}(p>0.05)$. CCL2 showed the least changes in expression compared to other cytokines following FIPV 79-1146 infection.

\section{Detection of immune-related protein expression in FCoV-positive cats \\ Clinical features of the cats}

The sampling of FCoV-positive cats was carried out at the University Veterinary Hospital-Universiti Putra Malaysia (UVH-UPM) over 1 year. Out of 150 cats, a total of 15 cats of different sex, age and breed that tested positive for high $(\geq S+2)$ FCoV antibody titer and FCoV RNA by RT-PCR but negative for FELV and FIV antibodies were considered for this study (Table 5). In addition, among the 15 FCoVpositive cats, nine cats were presented with peritoneal effusions, hence they were categorized into the effusive cohort. The remaining six cats were either asymptomatic (cat 6, 14 and 15) or having signs associated with non-effusive FIP (cat 2, 3 and 16) (Table 5).

Hematology examination of the nine cats with effusions showed evidence of thrombocytopenia, hyperbilirubinemia, hyperglobulinemia and hypoalbuminemia, with three of these cats also having lymphopenia and icterus. In addition, the cats had albumin/globulin (A: G) ratios of between 0.3-0.6. Cat 1 represents three healthy FCoVnegative cats aged 2-4 years that also tested negative for FIV and FELV antibodies.

\section{Detection of FCoV load in FCoV-seropositive cats}

FCoV was quantified by RT-qPCR in blood plasma and supernatant of the peritoneal effusion (PES) taken from the FCoV-seropositive cats. All of the cats, except for the FCoV-seronegative cats, had positive viral load in the plasma and PES (Table 6). Furthermore, the level of viral load in the PES was significantly higher $(p<0.05)$ than in the plasma for the majority of the cats (Table 6). Only two cats (cats 10 and 11) exhibited higher viral load in the plasma. Almost all cats with peritoneal effusions had higher plasma viral load $(p<0.05)$ compared to cats without peritoneal effusion.

Table 3 Relative expression of immune-related genes following FIPV 79-1146 infection of CRFK cells

\begin{tabular}{llllll}
\hline Time points (hpi) & CCL8 (MCP2) & CXCL10 (IP10) & CCL17 & MX1 & Viperin (RSAD2) \\
\hline 0 & $1 \pm 0^{\mathrm{a}}$ & $1 \pm 0^{\mathrm{a}}$ & $1 \pm 0^{\mathrm{a}}$ & $1 \pm 0^{\mathrm{a}}$ & $1 \pm 0^{\mathrm{c}}$ \\
3 & $21.67 \pm 0.57^{\mathrm{d}}$ & $13,341.2 \pm 197.75^{\mathrm{c}}$ & $39.68 \pm 1.61^{\mathrm{e}}$ & $4.49 \pm 0.62^{\mathrm{c}}$ & $-13.04 \pm 0^{\mathrm{a}}$ \\
12 & $3.41 \pm 0.07^{\mathrm{b}}$ & $8712.95 \pm 343.29^{\mathrm{b}}$ & $3.56 \pm 0^{\mathrm{b}}$ & $9.16 \pm 1.27^{\mathrm{d}}$ & $-7.82 \pm 0.02^{\mathrm{b}}$ \\
24 & $4.92 \pm 0.04^{\mathrm{c}}$ & $1,835,241.44 \pm 7662.16^{\mathrm{d}}$ & $22.87 \pm 0.69^{\mathrm{d}}$ & $2.69 \pm 0.11^{\mathrm{b}}$ & $5.72 \pm 0.03^{\mathrm{d}}$ \\
48 & $40,322.18 \pm 14.38^{\mathrm{f}}$ & $8,569,241.92 \pm 44,483.37^{\mathrm{e}}$ & $39.86 \pm 0.6^{\mathrm{e}}$ & $900.72 \pm 4.25^{\mathrm{f}}$ & $353.53 \pm 1.82^{\mathrm{e}}$ \\
72 & $21,651.02 \pm 510.17^{\mathrm{e}}$ & $8,776,535.79 \pm 30,986.02^{\mathrm{e}}$ & $8.51 \pm 0.44^{\mathrm{c}}$ & $517.06 \pm 5.38^{\mathrm{e}}$ & $583.3 \pm 9.86^{\mathrm{f}}$ \\
\hline
\end{tabular}

Note: Data are presented as means \pm SEM of three replicates from two independent experiments. Different alphabets above the data indicate significant difference following Duncan post hoc comparison of each column $(p<0.05)$. Relative expression $(\Delta \Delta C q)$ was calculated by normalizing with the reference gene (GAPDH) and the negative controls 
Table 4 Measurement of immune-related protein concentrations (pg/ml) in FIPV 79-1146-infected CRFK cells at different time points

\begin{tabular}{lllll}
\hline Time points (hpi) & CXCL8 (IL8) & CXCL1 (KC) & CCL5 (RANTES) & CCL2 (MCP1) \\
\hline 0 & $465.33 \pm 2.14^{\mathrm{b}}$ & $9.23 \pm 0.02^{\mathrm{a}}$ & $22.63 \pm 0.27^{\mathrm{c}}$ & $913.03 \pm 0.005^{\mathrm{a}}$ \\
3 & $166.75 \pm 25.74^{\mathrm{a}}$ & $28.55 \pm 9.21^{\mathrm{b}}$ & $8.35 \pm 0.004^{\mathrm{a}}$ & $960.84 \pm 0.005^{\mathrm{b}}$ \\
12 & $444.32 \pm 3.03^{\mathrm{b}}$ & $8.32 \pm 0.01^{\mathrm{a}}$ & $31.18 \pm 0.61^{\mathrm{d}}$ & $923.22 \pm 0.004^{\mathrm{a}}$ \\
24 & $1564.5 \pm 45^{\mathrm{c}}$ & $151.55 \pm 9.98^{\mathrm{c}}$ & $16.75 \pm 0.73^{\mathrm{b}}$ & $994.92 \pm 7.38^{\mathrm{b}}$ \\
48 & $1499.5 \pm 82.34^{\mathrm{c}}$ & $119.02 \pm 12.54^{\mathrm{c}}$ & $2470 \pm 114.67^{\mathrm{f}}$ & $1068.5 \pm 41.67^{\mathrm{c}}$ \\
72 & $2551 \pm 93.33^{\mathrm{d}}$ & $334.83 \pm 9.49^{\mathrm{d}}$ & $126.6 \pm 2.4^{\mathrm{e}}$ & $1050 \pm 0.001^{\mathrm{c}}$ \\
\hline
\end{tabular}

Note: Data are represented as means \pm SEM of three replicates from two independent experiments. Different alphabets above the data indicate significant difference following Duncan post hoc comparison of each column $(p<0.05)$. Peak expression levels of the cytokines were detected at 48 and/or 72 hpi

\section{Expression profiles of immune-related genes in PBMC}

The expression profiles of five immune-related genes, which were analyzed following in vitro infection of CRFK cells, were also analyzed in the PBMC and PE cells isolated from the FCoV-positive cats. In addition to normalization to GAPDH, the relative expression of the immune-related genes were normalized to the negative controls. As shown in Table 7, expression of all the genes except for CCL17 were detected in the PBMC of the sampled cats. However, gene expression levels varied among the cats. Most of the cats did not express or expressed very low levels of CCL8 and CXCL10 compared to healthy cats, except for cats 2,3 and 5 .

The expression of MX1 was detected in all FCoVseropositive cats but not in healthy cats, and higher expression levels were detected in FCoV-positive cats with effusions (Table 7). Although viperin functions as an IFN- induced antiviral protein, similar to MX1, different patterns of viperin expression was observed. In addition, five out of six cats without signs of effusion showed downregulation of viperin compared to control cats (Table 7). Nevertheless, in cats with effusions, expression of viperin showed a trend similar that of MX1. In addition, a majority of the FCoV-positive cats with effusions showed markedly elevated expression levels of MX1 and viperin. As expected, the FCoV-negative cats did not express any of the analyzed immune-related genes, except for viperin.

\section{Expression profiles of immune-related genes in peritoneal effusion cells}

No distinct expression pattern was observed in the cellular component of PE collected from FCoV-positive cats (Table 8). However, high expression of CCL17 was detected in PE samples from three out of eight FCoV-

Table 5 Demographic and clinical features of the cats considered for this study

\begin{tabular}{|c|c|c|c|c|c|c|c|c|}
\hline ID & Age & Sex & Breed & FCoV titer & FELV /FIV titer & Body temperature ${ }^{\circ} \mathrm{C}$ & Peritoneal effusion & $A: G$ ratio \\
\hline 1 & $2-4$ years & $\mathrm{F}$ & DSH & 0 & - & - & - & NA \\
\hline 2 & 1 year & M & Persian & S2+ & - & N/A & - & 0.6 \\
\hline 3 & 7 months & M & Persian & S3+ & - & N/A & - & NA \\
\hline 6 & 8 months & $\mathrm{F}$ & DSH & S5+ & - & N/A & - & NA \\
\hline 14 & 2 years & M & DSH & S5+ & - & N/A & - & NA \\
\hline 15 & 2 years & $\mathrm{F}$ & DSH & S5+ & - & N/A & - & NA \\
\hline 16 & 8 months & $\mathrm{F}$ & Persian & S5+ & - & 37.9 & - & 0.3 \\
\hline 4 & 2 years & M & DSH & S3+ & - & N/A & + & NA \\
\hline 7 & 7 months & M & Maine coon & S5+ & - & 37.3 & + & 0.3 \\
\hline 8 & 9 months & M & DSH & S4+ & - & 39.2 & + & 0.4 \\
\hline 9 & 3 years & M & DSH & S5+ & - & 38.6 & + & 0.6 \\
\hline 5 & 2 years & M & DSH & S5+ & - & 39.8 & + & 0.3 \\
\hline 10 & 8 months & M & DSH & S5+ & - & N/A & + & 0.3 \\
\hline 11 & 10 months & M & Maine coon & S4+ & - & 40.5 & + & 0.3 \\
\hline 12 & 1 year & M & Maine coon & S4+ & - & 38.3 & + & 0.5 \\
\hline 13 & 11 months & M & Persian & S5+ & - & 40.0 & + & 0.4 \\
\hline
\end{tabular}

Note: NA not available, DSH Domestic short hair, A:G Albumin/Globulin, $F$ Female, $M$ Male, FCoV scoring of S2+ titer low positive reaction, $\geq S 3+$ titer positive reaction, $\geq S 5+$ titer high positive reaction 
Table 6 Detection of FCoV load in plasma and supernatant of peritoneal effusion

\begin{tabular}{|c|c|c|c|}
\hline \multirow[t]{2}{*}{ Cat status } & \multirow[t]{2}{*}{ Cat ID } & \multicolumn{2}{|c|}{$\begin{array}{l}\text { FCoV copy number } \\
{[\text { Mean } \pm \text { SEM }(\log 10)]}\end{array}$} \\
\hline & & Plasma & PES \\
\hline Negative controls & $1^{*}$ & $-{ }^{a}$ & - \\
\hline \multirow[t]{6}{*}{ Non effusive } & 2 & $9.6 \pm 0.05^{b}$ & - \\
\hline & 3 & $10.73 \pm 0.06^{\text {cdefg }}$ & - \\
\hline & 6 & $10.41 \pm 0.82^{\text {cde }}$ & - \\
\hline & 14 & $10.25 \pm 0.17^{c}$ & - \\
\hline & 15 & $10.53 \pm 0.01^{\text {cde }}$ & - \\
\hline & 16 & $10.92 \pm 0.34^{\text {cdefgh }}$ & - \\
\hline \multirow[t]{9}{*}{ Effusive } & 4 & $11.06 \pm 0.28^{\text {efghi }}$ & $\mathrm{N} / \mathrm{A}$ \\
\hline & 7 & $11.31 \pm 0.33^{g h i}$ & $14.16 \pm 0.05^{1}$ \\
\hline & 8 & $10.74 \pm 0.09^{\text {cdefg }}$ & $13.01 \pm 0.04^{k}$ \\
\hline & 9 & $11.72 \pm 0.06^{\mathrm{ij}}$ & $12.13 \pm 0.18^{j}$ \\
\hline & 5 & $11.28 \pm 0.31^{\text {fghi }}$ & $13.21 \pm 0.05^{k}$ \\
\hline & 10 & $12.13 \pm 0.35^{j}$ & $10.6 \pm 0.65^{\text {cdef }}$ \\
\hline & 11 & $10.99 \pm 0.07^{\text {defgh }}$ & $10.31 \pm 0.09^{c d}$ \\
\hline & 12 & $11.57 \pm 0.28^{h i j}$ & $11.69 \pm 0.19^{\mathrm{ij}}$ \\
\hline & 13 & $10.78 \pm 0.74^{\text {cdefg }}$ & $12.02 \pm 0.05^{j}$ \\
\hline
\end{tabular}

N/A not available, PES supernatant of peritoneal effusion ${ }^{*}$ Cat 1 represents three healthy cats as negative controls Note: Data are presented as means \pm SEM of three replicates. Different alphabets denote significant difference $(p<0.05)$ following Duncan post hoc analysis positive cats with effusions. Meanwhile, cat 8, which showed the highest expression of CCL17, also exhibited the highest expression of MX1 and viperin as well. In addition, most of the cats that expressed MX1 also expressed viperin and CXCL10, suggesting the involvement of interferon-induced antiviral proteins; however, their expression levels varied significantly among different cats.

\section{Expression profiles of immune-related proteins in serum and peritoneal effusion supernatant}

MILLIPLEX analysis of the serum and PES from the FCoV-positive cats revealed that all 19 immune-related proteins were detectable (Tables 9 and 10). However, no clear pattern was observed between the different levels of cytokines in cats with or without the presence of peritoneal effusions. Nevertheless, the expression of the immunerelated proteins was higher in PES than in serum.

Although no common pattern of expression was seen among the FCoV-positive cats, detected levels of the different immune-related proteins in serum were higher in cats with peritoneal effusions compared to non-effusive FCoV-positive cats. The expression of pro-inflammatory cytokines and chemokines, such as GM-CSF, IFN $\gamma$, IL8, $\mathrm{KC}$, RANTES, and MCP1, was readily detected in the serum of FCoV-positive cats (Table 9). The expression of IL1 $\beta$ and IL6 was not detected in the serum of the majority of the cats; however, these cytokines were detected in

Table 7 Relative expression profiles of immune-related genes in PBMC of FCoV-positive cats

\begin{tabular}{|c|c|c|c|c|c|}
\hline Cat status & Cat ID & CCL8 (MCP2) & CXCL10 (IP10) & $\mathrm{M} \times 1$ & Viperin (RSAD2) \\
\hline Negative & $1^{*}$ & $\mathrm{ND}$ & ND & ND & $1 \pm 0^{b c}$ \\
\hline \multirow[t]{6}{*}{ Non-effusive } & 2 & ND & $18.67 \pm 0.33^{b}$ & $6.79 \pm 1.8^{\mathrm{e}}$ & $-1.88 \pm 0.27^{b c}$ \\
\hline & 3 & $16.32 \pm 5.48^{c}$ & ND & $0.91 \pm 0.1^{c d}$ & ND \\
\hline & 6 & ND & ND & $0.03 \pm 0^{\mathrm{a}}$ & $-86.21 \pm 0.01^{a}$ \\
\hline & 14 & $0.42 \pm 0.02^{\mathrm{a}}$ & ND & $1.45 \pm 0.36^{d}$ & $-28.01 \pm 0.02^{b}$ \\
\hline & 15 & ND & ND & $0.58 \pm 0.04^{c}$ & $-94.34 \pm 0.01^{a}$ \\
\hline & 16 & ND & ND & $0.32 \pm 0.07^{b}$ & $-39.84 \pm 0.02^{b}$ \\
\hline \multirow[t]{9}{*}{ Effusive } & 4 & ND & ND & $0.05 \pm 0^{a}$ & ND \\
\hline & 7 & $0.1 \pm 0.05^{a}$ & $0.23 \pm 0.22^{a}$ & $13.62 \pm 5.07^{f g}$ & $4.87 \pm 1.39^{c d}$ \\
\hline & 8 & ND & ND & $3773.07 \pm 67.71^{j}$ & $437.28 \pm 31.23^{f}$ \\
\hline & 9 & ND & ND & $7309.7 \pm 52.55^{k}$ & $50.48 \pm 3.44^{e}$ \\
\hline & 5 & $1.08 \pm 0.38^{b}$ & $19.17 \pm 0^{c}$ & $19.14 \pm 0.02^{g h}$ & $4.95 \pm 0.31^{c d}$ \\
\hline & 10 & ND & ND & $56.48 \pm 13.47^{i}$ & $7.91 \pm 5.25^{\text {de }}$ \\
\hline & 11 & ND & ND & $6.79 \pm 0.74^{e f}$ & $-3.35 \pm 0.17^{c}$ \\
\hline & 12 & ND & ND & $16.37 \pm 5.13^{9}$ & $1.83 \pm 0.45^{\mathrm{bcd}}$ \\
\hline & 13 & ND & ND & $26.9 \pm 1.61^{h}$ & $10.16 \pm 1.08^{\mathrm{de}}$ \\
\hline
\end{tabular}

ND Not detected

*Average expression of three healthy cats as negative controls. Relative expression $(\Delta \Delta \mathrm{Cq})$ was calculated by normalizing to the reference gene (GAPDH) and negative controls

Note: Data are presented as means \pm SEM of three replicates. Different alphabets indicate significant difference following Duncan post hoc comparison of each column $(p<0.05)$ 
Table 8 Relative expression profiles of immune-related genes in cells from peritoneal effusion

\begin{tabular}{llllll}
\hline Cat ID & CCL8 (MCP2) & CXCL10 (IP10) & CCL17 & MX1 & Viperin (RSAD2) \\
\hline 7 & $1.77 \pm 0.29^{\mathrm{d}}$ & $2.14 \pm 0^{\mathrm{e}}$ & $0.37 \pm 0.19^{\mathrm{bc}}$ & $1.65 \pm 0.09^{\mathrm{c}}$ & $2.14 \pm 0^{\mathrm{e}}$ \\
8 & $0.29 \pm 0.06^{\mathrm{b}}$ & $0.57 \pm 0.2^{\mathrm{bc}}$ & $18.95 \pm 16.6^{\mathrm{cd}}$ & $11.24 \pm 0.82^{\mathrm{e}}$ & $13.31 \pm 1.98^{\mathrm{f}}$ \\
9 & $0.46 \pm 0.04^{\mathrm{bc}}$ & $0.36 \pm 0.1^{\mathrm{b}}$ & $12.69 \pm 6.01^{\mathrm{d}}$ & $0.58 \pm 0.02^{\mathrm{b}}$ & $0.03 \pm 0^{\mathrm{a}}$ \\
5 & $0.12 \pm 0.02^{\mathrm{a}}$ & $0.06 \pm 0.01^{\mathrm{a}}$ & $0.37 \pm 0.18^{\mathrm{cd}}$ & $0.61 \pm 0.03^{\mathrm{b}}$ & $0.34 \pm 0.02^{\mathrm{b}}$ \\
10 & $1.43 \pm 0.11^{\mathrm{d}}$ & $0.64 \pm 0.1^{\mathrm{bcd}}$ & $0 \pm 0^{\mathrm{a}}$ & $1.36 \pm 0.1^{\mathrm{c}}$ & $0.79 \pm 0.12^{\mathrm{c}}$ \\
11 & $0.1 \pm 0.04^{\mathrm{a}}$ & $0.85 \pm 0.07^{\mathrm{cd}}$ & $9.18 \pm 3.87^{\mathrm{d}}$ & $0.21 \pm 0.03^{\mathrm{a}}$ & $1.15 \pm 0.13^{\mathrm{d}}$ \\
12 & $4.62 \pm 0.08^{\mathrm{e}}$ & $2.21 \pm 0.38^{\mathrm{e}}$ & $0.03 \pm 0.03^{\mathrm{ab}}$ & $4.7 \pm 0^{\mathrm{d}}$ & $1.97 \pm 0.34^{\mathrm{e}}$ \\
13 & $0.79 \pm 0.1^{\mathrm{c}}$ & $1.04 \pm 0.14^{\mathrm{d}}$ & $1.83 \pm 1.17^{\mathrm{cd}}$ & $0.51 \pm 0.05^{\mathrm{b}}$ & $0.97 \pm 0.07^{\mathrm{cd}}$ \\
\hline
\end{tabular}

Note: Data are presented as means \pm SEM of three replicates. Different alphabets indicate significantly different groupings following Duncan post hoc comparison of each column $(p<0.05)$. Relative expression $(\Delta \Delta \mathrm{Cq})$ was calculated by normalizing to the reference gene (GAPDH) and negative controls

the PES of cats with peritoneal effusions (Table 10). TNF $\alpha$ production was detected in both FCoV-positive and negative cohorts. The production of this cytokine in the control cats could be due to an inflammatory process unrelated to $\mathrm{FCoV}$ infection, such as physiological stress [28]. In addition, the pro-inflammatory cytokine IL-18 was not consistently detected in both serum and PES. Unlike other immune-related proteins, serum levels of stem cell factor (SCF) were lower in the FCoV-positive cats compared to the control cats (Table 9).

\section{Discussion}

Feline infectious peritonitis (FIP) is one of the leading causes of death among young cats [1]. Since FIP is an immune-mediated viral disease, studies using immunological approaches are crucial for a better understanding of the illness, particularly by using clinical samples of FIP cases before further studies utilizing experimental infection in cats could be justified. Detection of FCoV antigen in affected tissues by immunohistochemistry remains the gold standard in the confirmation of FIP [2].

One of the limitations of this study is that definitive confirmation of FIP was not made due to the unavailability of post-mortem samples. Therefore, the cats were selected based on their FCoV antibody and antigen status. In addition, the selected FCoV-positive cats were grouped according to the presence of peritoneal effusions at the time of clinical evaluation. Although we could not confirm the status of FIP in these cats, this study provides a preliminary examination on the array of immune mediators that may be involved in the development of FIP. In this study, more than 20 immune mediators were characterized following FIPV 79-1146 infection of CRFK cells and in FCoV-positive cats. Different expression profiles of immune mediators were detected in FIPV 79-1146-infected CRFK cells and those from FCoV-positive cats. Furthermore, the CRFK cells were used to optimize the real-time PCR detection of the different immune-related genes and to detect interferon-related genes during viral infection.
Based on an NGS transcriptomic study, we showed that pro-inflammatory and interferon-related genes, namely CCL8 (MCP2), CXCL10 (IP10), CCL17, MX1 and viperin (RSAD2), were upregulated in FIPV 791146-infected CRFK cells [14]. In this study, we confirmed the upregulation of these genes using Taqman real-time PCR (Table 2); however, detected levels of expression varied, which could be due to the differences in the sensitivity of these different platforms. One of the genes of interest that was highly upregulated and associated with an increase in viral load is MX1, an interferoninduced GTP-binding protein. Previous studies have shown that MX1 is an interferon-inducible protein found in humans and various animals that mediates resistance against RNA viruses [29]. In this study, we showed that mRNA expression of MX1 was significantly upregulated at 48 and $72 \mathrm{hpi}$ and found to be correlated with the viral load at 48 hpi (Tables 2 and 3). Previous studies have also shown that the antiviral role of this gene is related to IFN $\alpha$ and $\beta$ (IFN type 1 ) induction and GTPase pathways [19]. Similar to MX1, RSAD2, which is also known as viperin, is a gene that encodes for an IFN-induced antiviral protein [30]. However, unlike MX1, which is activated by type I IFN, viperin is induced by different types of IFN [31, 32]. In fact, the expression of viperin can be induced by double-stranded RNA analogs such as poly I:C, lipopolysaccharides and by infection with a broad range of both RNA and DNA viruses, indicating the diverse role of viperin during infection [31, 32]. The importance of this finding is not clear; nevertheless, studies have shown that viruses such as Japanese Encephalitis Virus (JEV) [33] and Dengue Virus type 2 (DENV-2) [34] can downregulate antiviral innate immune responses such as viperin and other IFNinducible protein expression [31, 32]. Further studies are required to measure type I IFN levels in cats with FIP.

The clinical relevance of the observed variations in MX1 and viperin expression to the development of FIP is unknown. However, a study has shown that expression of viperin is crucial for optimal Th2 cell 


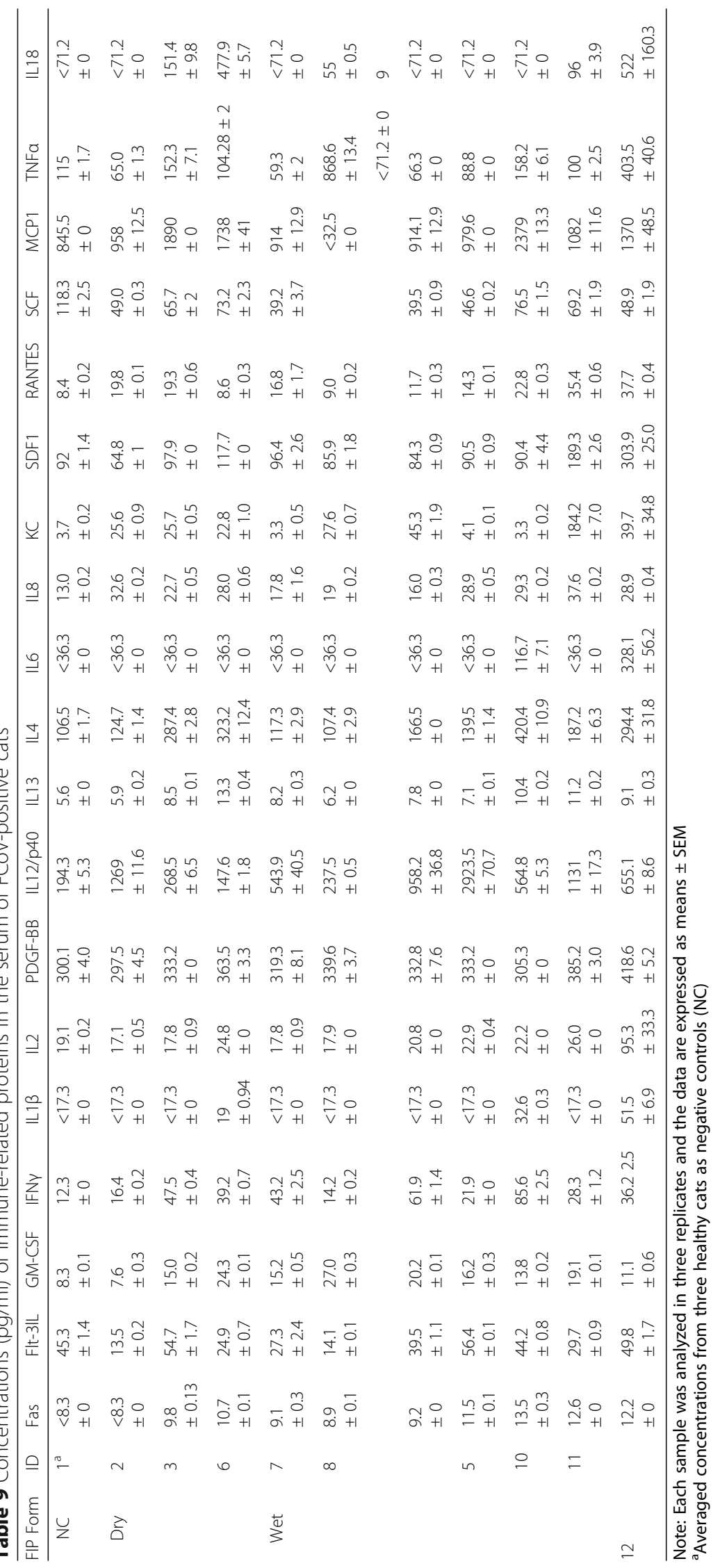




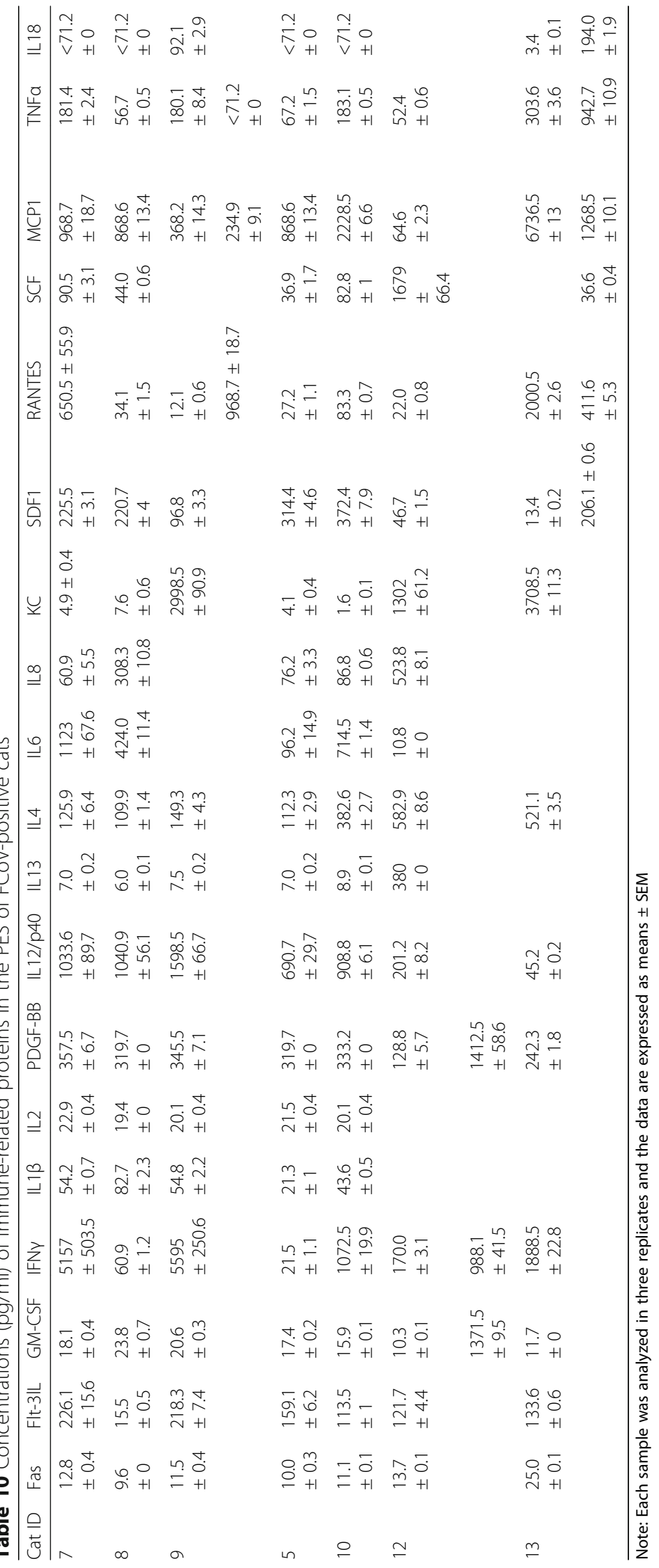


response in mice [35]. Hence, it is essential to further evaluate the importance of this finding in FIP cats. Earlier studies have proposed that the fundamental difference in the immune profiles of dry and wet forms of FIP is based on the predominant $\mathrm{T}$ cell responses. Cats with the dry form of FIP have a higher number of Th1 cells for the induction of CMI response, while cats with the wet form of FIP generally showed Th2-type response that leads to humoral immune response [13, 19].

The majority of FIP cases involve the presence of abdominal effusion, which was observed in eight out of 15 FCoV-positive cats sampled in this study [2]. Based on the pathogenesis of FIP, the accumulation of fluids in the peritoneal cavity of these cats is most probably due to the accumulation of the infected macrophages in the inter-venular space and venule walls $[1,10]$. Activated and FCoV-infected monocytes can induce phlebitis through the paracrine and autocrine action of CD18, IL-1 $\beta$ and TNF $\alpha$ [11]. In addition, higher secretion of vascular endothelial growth factor (VEGF) has been associated with an increased production of effusion in cats with FIP [36]. Also, studies have shown that PE of cats diagnosed with FIP consisted primarily of macrophages and neutrophils with a low number of lymphocytes [37]. This study is in agreement with another study that reported a higher viral load in the supernatants of PE compared to those derived from the blood component of affected cats (Table 6) [15]. In addition, as expected, this study detected high expression of proinflammatory cytokines and chemokines, namely GMCSF, IFN $\gamma$, IL8, KC, RANTES and MCP1, which are secreted mainly by monocytes/macrophages. The detection of CCL17 in the cell component of PE but not in PBMC indicated the inflammatory nature of the activated cells such as macrophages and dendritic cells (DC) present in the PE which may play an important role in the activation of Th2 cells [38, 39]. Furthermore, the lack of CCL17 expression, a chemokine that is primarily expressed in Th2 cells of cats with allergic inflammation [40], in the PBMC of the cats sampled in this study suggests a local rather than systemic response to the virus as also observed in other studies [17, 41, 42]. Further studies are warranted to confirm the expression of CCL17 by the activated cells from the PE of FIP cats. In addition, the downregulation of SCF (Table 9) is probably associated with the reduction of DC in cats with FIP, since SCF and Flt-3 L are important cytokines for the ex vivo propagation of human and mice DC [43, 44]. It was known that DC could be infected by FCoV; however, the role of SCF and Flt-3 L in FIPV infection warrants further examination [45].
In this study, the immune mediator protein levels vary between individual cats within the different cohorts (Tables 9 and 10). These findings were expected as biological individual variation could occur and has been observed in several other natural and experimental FIPV infections [12, 19]. Nevertheless, the expression of pro-inflammatory cytokines, namely IL1 $\beta$ and IL6, was more readily detected in the PES rather than the serum of the cats diagnosed with FIP. This finding is in agreement with previous studies that showed IL1 and IL6 can be detected in the serum and PE of FIP cases but not in those of healthy cats [18]. Besides, previous studies have shown that IL1 $\beta$ is related to CNS involvement and can only be detected in the inflammatory cells in the brain [19]. In this study, we found that IL-18, a proinflammatory cytokine in the IL-1 family that plays a major role in the activation of NK and T cells [46], was not readily detected in both serum and PES. The upregulation of TNF $\alpha$ protein in the serum and PES of some of the cats was in line with findings by previous studies that detected an increase in TNF $\alpha$ mRNA in abdominal effusions and PBMC of FIPpositive cats [14]. In addition, it has been suggested that this cytokine is responsible for $\mathrm{T}$ cell apoptosis $[14,21]$. Hence, the role of these cytokines in FCoVpositive cats requires further evaluation. Interestingly, most of the FCoV-positive cats in this study have increased Fas serum levels, which may suggest a possible role of Fas in $\mathrm{T}$ cell apoptosis observed in FIP, as apoptosis can be induced by overexpression of Fas during viral infection [47].

\section{Conclusions}

In conclusion, this study has established some insights on the different expression of immune mediators in FCoV-positive cats, where several immune mediators including pro-inflammatory cytokines, Th1-like cytokines, and IFN-related antiviral proteins were found to be highly expressed. In addition, no clear indication of Th1 and Th2 imbalance was detected in the various samples analyzed in this study. However, in general, MX1, viperin, CXCL10, CCL8, RANTES, KC, MCP1, IL8, GM-CSF and IFN $\gamma$ were readily detected in FCoVpositive cats whereby MX1 and viperin expression was higher in FCoV-positive cats with peritoneal effusions. Future studies on FIP confirmed cases need to be carried out to further establish the importance of the different immune mediators in the development of FIP.

\footnotetext{
Abbreviations

3'UTR: 3' untranslated region; BLAST: Basic local alignment search tool; CMI: Cell-mediated immunity; CRFK: Crandell-Reese feline kidney; DC: Dendritic cell; FCoV: Feline coronavirus; FELV: Feline leukemia virus; FIP: Feline infectious peritonitis; FIPV: Feline infectious peritonitis virus;
} 
FIV: Feline immunodeficiency virus; hpi: Hours post inoculation; IACUC: Institutional animal care and use committee; NGS: Next-generation sequencing; PBMC: Peripheral blood mononuclear cell; PE: Peritoneal effusion; PES: Peritoneal effusion supernatant; GRT-PCR: Quantitative reverse transcriptase polymerase chain reaction; SARS: Severe acute respiratory syndrome; SPF: Specific-pathogen-free; SPSS: Statistical package for the social sciences; $\mathrm{TCID}_{50}$ : Tissue culture infectious dose 50; UNG: Uracil-N-glycosylase

\section{Acknowledgements}

The authors would like to thank Dr. Tan Sheau Wei for her technical assistance in the RT-qPCR analysis of the samples.

\section{Funding}

This study was supported by a PRGS Grant No: 5530600 from the Ministry of Education, Malaysia. The funding body has no specific role in the study design, data collection and analysis, decision to publish, or preparation of the manuscript.

\section{Availability of data and materials}

All data generated or analyzed during this study can be found in the tables and figures of the manuscript.

\section{Authors' contributions}

NS and ARO co-defined the research theme. NS and AH designed and carried out the laboratory experiments, analyzed and interpreted the data and drafted the manuscript. SWN, GTS and FMK contributed at different stages of the experiments, depending on the fields of expertise. NS, AH ARO and FMK revised the paper critically for important intellectual content. All authors have seen and approved the manuscript.

\section{Competing interests}

The authors declare that they have no competing interests.

\section{Consent for publication}

Not applicable.

\section{Ethics approval and consent to participate}

Prior to performing the in vivo phase of the study, permission was obtained from the Institutional Animal Care and Use Committee (IACUC) from the office of the Deputy Vice-Chancellor of Research and Innovation, Universiti Putra Malaysia. Approval letter of the current project was issued on 23rd of July 2014 with the reference number UPM/IACUC/AUP-R040/2014. Consent was obtained from the cat owners prior to sample collection. Therefore, the use of the cats in this study met the criteria of animal welfare regulations in Malaysia.

\section{Publisher's Note}

Springer Nature remains neutral with regard to jurisdictional claims in published maps and institutional affiliations.

\section{Author details}

'Institute of Bioscience, Universiti Putra Malaysia, Serdang, Selangor, Malaysia. ${ }^{2}$ Faculty of Veterinary Medicine, Universiti Putra Malaysia, Serdang, Selangor, Malaysia. ${ }^{3}$ Leonard Davis School of Gerontology, University of Southern California, Los Angeles, CA, USA.

Received: 21 March 2016 Accepted: 3 April 2017

Published online: 07 April 2017

\section{References}

1. Pedersen NC. A review of feline infectious peritonitis virus infection: 1963-2008. J Feline Med Surg. 2009;11(4):225-58.

2. Kipar A, Meli ML. Feline infectious peritonitis: still an enigma? Vet Pathol. 2014;51(2):505-26.

3. Kipar A, Meli ML, Baptiste KE, Bowker L, Lutz H. Sites of feline coronavirus persistence in healthy cats. J Gen Virol. 2010;91(Pt 7):1698-707.

4. Pedersen NC, Liu H, Scarlett J, Leutenegger CM, Golovko L, Kennedy H, Kamal FM. Feline infectious peritonitis: role of the feline coronavirus $3 \mathrm{c}$ gene in intestinal tropism and pathogenicity based upon isolates from resident and adopted shelter cats. Virus Res. 2012;165(1):17-28.
5. Chang HW, Egberink HF, Halpin R. Spike protein fusion peptide and feline coronavirus virulence. Emerg Infect Dis. 2012;18:1089.

6. Lewis CS, Porter E, Matthews D, Kipar A, Tasker S, Helps CR, Siddell SG. Genotyping coronaviruses associated with feline infectious peritonitis. J Gen Virol. 2015;96(Pt 6):1358-68.

7. Bank-Wolf BR, Stallkamp I, Wiese S, Moritz A, Tekes G, Thiel HJ. Mutations of $3 \mathrm{C}$ and spike protein genes correlate with the occurrence of feline infectious peritonitis. Vet Microbiol. 2014;173(3-4):177-88.

8. Chang HW, Egberink HF, Rottier PJ. Sequence analysis of feline coronaviruses and the circulating virulent/avirulent theory. Emerg Infect Dis. 2011;17(4):744-6.

9. de Groot-Mijnes JD, van Dun JM, van der Most RG, de Groot RJ. Natural history of a recurrent feline coronavirus infection and the role of cellular immunity in survival and disease. J Virol. 2005;79(2):1036-44.

10. Kipar A, Bellmann S, Kremendahl J, Kohler K, Reinacher M. Cellular composition, coronavirus antigen expression and production of specific antibodies in lesions in feline infectious peritonitis. Vet Immunol Immunopathol. 1998;65(2-4):243-57.

11. Kipar A, May H, Menger S, Weber M, Leukert W, Reinacher M. Morphologic features and development of granulomatous vasculitis in feline infectious peritonitis. Vet Pathol. 2005;42(3):321-30.

12. Kipar A, Meli ML, Failing K, Euler T, Gomes-Keller MA, Schwartz D, Lutz H, Reinacher M. Natural feline coronavirus infection: differences in cytokine patterns in association with the outcome of infection. Vet Immunol Immunopathol. 2006;112(3-4):141-55.

13. Dean GA, Olivry T, Stanton C, Pedersen NC. In vivo cytokine response to experimental feline infectious peritonitis virus infection. Vet Microbiol. 2003;97(1-2):1-12

14. Takano T, Hohdatsu T, Hashida Y, Kaneko Y, Tanabe M, Koyama H. A "possible" involvement of TNF-alpha in apoptosis induction in peripheral blood lymphocytes of cats with feline infectious peritonitis. Vet Microbiol. 2007;119(2-4):121-31.

15. Pedersen NC, Eckstrand C, Liu H, Leutenegger C, Murphy B. Levels of feline infectious peritonitis virus in blood, effusions, and various tissues and the role of lymphopenia in disease outcome following experimental infection. Vet Microbiol. 2015;175(2-4):157-66.

16. Gelain ME, Meli M, Paltrinieri S. Whole blood cytokine profiles in cats infected by feline coronavirus and healthy non-FCoV infected specific pathogen-free cats. J Feline Med Surg. 2006;8(6):389-99.

17. Goitsuka R, Furusawa S, Mizoguchi M, Hasegawa A. Detection of interleukin 1 in ascites from cats with feline infectious peritonitis. J Vet Med Sci. 1991;53(3):487-9.

18. Goitsuka R, Ohashi T, Ono K, Yasukawa K, Koishibara Y, Fukui H, Ohsugi Y, Hasegawa A. IL-6 activity in feline infectious peritonitis. J Immunol. 1990;144(7):2599-603.

19. Foley JE, Rand C, Leutenegger C. Inflammation and changes in cytokine levels in neurological feline infectious peritonitis. J Feline Med Surg. 2003;5(6):313-22.

20. Harun MS, Kuan CO, Selvarajah GT, Wei TS, Arshad SS, Hair Bejo M, Omar AR. Transcriptional profiling of feline infectious peritonitis virus infection in CRFK cells and in PBMCs from FIP diagnosed cats. Virol J. 2013;10(1):329.

21. Shuid AN, Safi N, Haghani A, Mehrbod P, Haron MS, Tan SW, Omar AR. Apoptosis transcriptional mechanism of feline infectious peritonitis virus infected cells. Apoptosis. 2015:20(11):1457-70.

22. Herrewegh AA, Smeenk I, Horzinek MC, Rottier PJ, de Groot RJ. Feline coronavirus type II strains 79-1683 and 79-1146 originate from a double recombination between feline coronavirus type I and canine coronavirus. J Virol. 1998;72(5):4508-14.

23. Herrewegh AA, de Groot RJ, Cepica A, Egberink HF, Horzinek MC, Rottier PJ. Detection of feline coronavirus RNA in feces, tissues, and body fluids of naturally infected cats by reverse transcriptase PCR. J Clin Microbiol. 1995;33(3):684-9.

24. Addie D. The diagnosis and prevention of FIP and recent research into feline coronavirus shedding. In: Proceedings of the 8th annual congress of the European Society of Veterinary Internal Medicine, Vienna, Austria: 1998; 1998. p. 110-7.

25. Choong OK, Mehrbod P, Tejo BA, Omar AR. In vitro antiviral activity of circular triple helix forming oligonucleotide RNA towards feline infectious peritonitis virus replication. Biomed Res Int. 2014;2014:654712.

26. Hockett RD, Kilby JM, Derdeyn CA, Saag MS, Sillers M, Squires K, Chiz S, Nowak MA, Shaw GM, Bucy RP. Constant mean viral copy number per infected cell in tissues regardless of high, low, or undetectable plasma HIV RNA. J Exp Med. 1999;189(10):1545-54. 
27. Pontius JU, Mullikin JC, Smith DR, Agencourt Sequencing T, Lindblad-Toh $\mathrm{K}$, Gnerre S, Clamp M, Chang J, Stephens R, Neelam B, et al. Initial sequence and comparative analysis of the cat genome. Genome Res. 2007;17(11):1675-89.

28. Himmerich H, Fischer J, Bauer K, Kirkby KC, Sack U, Krugel U. Stress-induced cytokine changes in rats. Eur Cytokine Netw. 2013;24(2):97-103.

29. Sadler AJ, Williams BR. Interferon-inducible antiviral effectors. Nat Rev Immunol. 2008;8(7):559-68.

30. Fitzgerald KA. The interferon inducible gene: Viperin. J Interferon Cytokine Res. 2011;31(1):131-5.

31. Duschene KS, Broderick JB. Viperin: a radical response to viral infection. Biomol Concepts. 2012;3(3):255-66.

32. Wong MT, Chen SS: Emerging roles of interferon-stimulated genes in the innate immune response to hepatitis $\mathrm{C}$ virus infection. Cell $\mathrm{Mol}$ Immunol. 2014;13(1):11-35.

33. Chan $Y L$, Chang $T H$, Liao CL, Lin $Y L$. The cellular antiviral protein viperin is attenuated by proteasome-mediated protein degradation in Japanese encephalitis virus-infected cells. J Virol. 2008;82(21):10455-64.

34. Helbig KJ, Carr JM, Calvert JK, Wati S, Clarke JN, Eyre NS, Narayana SK, Fiches GN, McCartney EM, Beard MR. Viperin is induced following dengue virus type-2 (DENV-2) infection and has anti-viral actions requiring the C-terminal end of viperin. PLoS Negl Trop Dis. 2013;7(4):e2178

35. Qiu LQ, Cresswell P, Chin KC. Viperin is required for optimal Th2 responses and T-cell receptor-mediated activation of NF-kappaB and AP-1. Blood. 2009;113(15):3520-9.

36. Takano T, Ohyama T, Kokumoto A, Satoh R, Hohdatsu T. Vascular endothelial growth factor (VEGF), produced by feline infectious peritonitis (FIP) virusinfected monocytes and macrophages, induces vascular permeability and effusion in cats with FIP. Virus Res. 2011;158(1-2):161-8.

37. Pedersen NC. An update on feline infectious peritonitis: diagnostics and therapeutics. Vet J. 2014;201(2):133-41.

38. Katakura T, Miyazaki M, Kobayashi M, Herndon DN, Suzuki F. CCL17 and IL-10 as effectors that enable alternatively activated macrophages to inhibit the generation of classically activated macrophages. J Immunol. 2004;172(3):1407-13.

39. Alferink J, Lieberam I, Reindl W, Behrens A, Weiss S, Huser N, Gerauer K, Ross R, Reske-Kunz AB, Ahmad-Nejad P, et al. Compartmentalized production of CCL17 in vivo: strong inducibility in peripheral dendritic cells contrasts selective absence from the spleen. J Exp Med. 2003;197(5):585-99.

40. Maeda S, Okayama T, Ohmori K, Masuda K, Ohno K, Tsujimoto H. Molecular cloning of the feline thymus and activation-regulated chemokine CDNA and its expression in lesional skin of cats with eosinophilic plaque. J Vet Med Sci. 2003;65(2):275-8.

41. Takano T, Azuma N, Satoh M, Toda A, Hashida Y, Satoh R, Hohdatsu T. Neutrophil survival factors (TNF-alpha, GM-CSF, and G-CSF) produced by macrophages in cats infected with feline infectious peritonitis virus contribute to the pathogenesis of granulomatous lesions. Arch Virol. 2009:154(5):775-81.

42. Giordano A, Paltrinieri S. Interferon-gamma in the serum and effusions of cats with feline coronavirus infection. Vet J. 2009;180(3):396-8.

43. Reyes M, Lund T, Lenvik T, Aguiar D, Koodie L, Verfaillie CM. Purification and ex vivo expansion of postnatal human marrow mesodermal progenitor cells. Blood. 2001;98(9):2615-25.

44. Laouar Y, Welte T, Fu X-Y, Flavell RA. STAT3 is required for Flt3L-dependent Dendritic cell differentiation. Immunity. 2003;19(6):903-12.

45. Tekes G, Hofmann-Lehmann R, Stallkamp I, Thiel V, Thiel HJ. Genome organization and reverse genetic analysis of a type I feline coronavirus. $J$ Virol. 2008;82(4):1851-9.

46. Dinarello CA, Novick D, Kim S, Kaplanski G. Interleukin-18 and IL-18 binding protein. Front Immunol. 2013;4:289.

47. Katsikis PD, Wunderlich ES, Smith CA, Herzenberg LA, Herzenberg LA. Fas antigen stimulation induces marked apoptosis of T lymphocytes in human immunodeficiency virus-infected individuals. J Exp Med. 1995;181(6):2029-36.

\section{Submit your next manuscript to BioMed Central and we will help you at every step:}

- We accept pre-submission inquiries

- Our selector tool helps you to find the most relevant journal

- We provide round the clock customer support

- Convenient online submission

- Thorough peer review

- Inclusion in PubMed and all major indexing services

- Maximum visibility for your research

Submit your manuscript at www.biomedcentral.com/submit
Biomed Central 